CLINICAL ETHICS

\title{
Facing requests for euthanasia: a clinical practice guideline
}

\author{
C Gastmans, F Van Neste, P Schotsmans
}

J Med Ethics 2004;30:212-217. doi: 10.1136/jme.2003.005082

On 23 September 2002, the Belgian law on euthanasia came into force. This makes Belgium the second country in the world (after the Netherlands) to have an Act on euthanasia. Even though there is currently legal regulation of euthanasia in Belgium, very little is known about how this legal regulation could be translated into care for patients who request euthanasia.

See end of article for authors' affiliations .....................

Correspondence to: Professor C Gastmans, Centre for Biomedical Ethics and Law, Faculty of Medicine, Kapucijnenvoer 35, Leuven 3000, Belgium; chris.gastmans@ med.kuleuven.ac.be

Received

30 May 2003

Revised version received 17 October 2003

Accepted for publication

21 October 2003 mmediately following the approval of the Belgian Act on euthanasia, Caritas Flanders sent a clinical practice guideline to 1213 affiliated institutions. The clinical practice guideline makes explicit how medical and nursing expertise could effectively be employed in the interdisciplinary care context, so that the competent, terminally ill patient who requests euthanasia receives the best human care available. Requests for euthanasia from incompetent people (advance directive) or from people who are not terminally ill-which are also regulated by law-fall outside the scope of this guideline. Before sketching the contents of the clinical practice guideline, some relevant aspects of the Belgian Euthanasia Act, the context in which this guideline should be placed, and how it was developed must first be clarified.

\section{EUTHANASIA IN BELGIUM Belgian Euthanasia Act}

According to Article 2 of the Belgian Act, euthanasia is defined as intentionally terminating life by someone other than the person concerned, at the latter's request.

The Act determines that the physician who performs euthanasia commits no criminal offence when he has reassured himself that all conditions are fulfilled and when he has respected the conditions and procedures as provided in this Act (Article 3.1):

- The patient has attained the age of majority or is an emancipated minor, and is legally competent and conscious at the moment of making the request.

- The request is voluntary, well considered and repeated, and not the result of any external pressure.

- The patient is in a medically futile condition of constant and unbearable physical or mental suffering that cannot be alleviated, resulting from a serious and incurable disorder caused by illness or accident.
Article 3.2 contains a very detailed description of the requirements that have to be respected by the physician who performs euthanasia:

- Inform the patient about their condition of health and their life expectancy; discuss with the patient their request for euthanasia and the possible therapeutic and palliative courses of action and their consequences.

- Be certain of the patient's constant physical or mental suffering and of the durable character of their request.

- Consult another physician about the serious and incurable character of the disorder and inform them about the reasons for this consultation; inform the patient about the results of this consultation.

- Discuss the request with the nursing team or its members.

- Discuss the patient's request, if the patient so desires, with relatives appointed by the patient.

The physician who has performed euthanasia is requested to fill in a registration form, and to deliver it within four working days to the Federal Control and Evaluation Committee (Article 5).

No physician may be compelled to perform euthanasia. No other person may be compelled to assist in performing euthanasia (Article 14).

The Euthanasia Act contains some sections concerning requests for euthanasia from incompetent persons (advance directives) (Article 4.12 ) and from persons who are not terminally ill (Article 3.3). These sections fall outside the scope of this article.

\section{Why this clinical practice guideline was developed}

Caritas Flanders is a Flemish Christian inspired umbrella organisation for cooperation and consultation in health care and public welfare. Caritas Flanders groups 62 general hospitals, 94 mental healthcare institutions, 326 geriatric care institutions, 397 facilities for handicapped people, and 344 facilities for public welfare.

The clinical practice guideline was drafted by the ethics committee of Caritas Flanders. The authors of this article are secretary, president, and vice president of the ethics committee. The committee began preparing the guideline in January 2000 after six senators from the government coalition had, on 20 December 1999, submitted a joint legislative proposal concerning euthanasia to the Belgian senate. Another fact that urged the development of this guideline was the publication in November 2000 of a nationwide survey, wherein it was observed and estimated that 640 deaths in Flanders in 1998 
resulted from euthanasia. ${ }^{1}$ The debate on euthanasia and the research findings led Caritas Flanders to believe that caregivers will increasingly be confronted with euthanasia requests and will therefore be more involved in care for these patients.

The ethics committee's objective was to find a publicly understandable and ethically well founded answer to the question of how caregivers should best ensure a dignified end to life. More specifically, the committee hoped to arrive at an ethically justifiable method of shared clinical-ethical decision making when confronted with a request for euthanasia from a competent, terminally ill patient. Restricting the guideline to requests for euthanasia from competent, terminally ill patients permits the committee to develop a more focused guideline.

\section{How this clinical practice guideline was developed}

The guideline was developed according to a consensus meeting (opinion based) method. According to this central (or top down) approach, a selected group of experts attempt to achieve consensus on a specific aspect of medical care-for example, euthanasia. ${ }^{2}{ }^{3}$ The following steps undertaken in the development of the clinical practice guideline can be differentiated:

- In January 2000 the ethics committee of Caritas Flanders organised a first internal brainstorm session about the content and the functioning of a clinical practice guideline with regards to caring for patients who request euthanasia. The ethics committee is made up of physicians, nurses, directors of health care institutions, ethicists, jurists, and pastoral workers.

- Keeping in mind the comments that came forth out of the brainstorm session, the secretary undertook a literature study of the concerned ethical aspects of caring for patients who request euthanasia and the role of a clinical practice guideline therein.

- The literature study was extensively commented upon by the ethics committee. The most important point of discussion was what the relation between palliative care and euthanasia was.

- On the basis of the literature study, the secretary developed a first draft of the clinical practice guideline. This draft was given to experts in the field of palliative care (three physicians and three nurses) to comment upon. They were asked whether they agreed with the structure and the content of the guideline. Furthermore the ethical advisor of the Flemish Palliative Care Federation was asked to comment on this draft of the guideline. During these discussions, the concept of the palliative filter was introduced.

- On the basis of these collected comments, the secretary developed a second draft that was more precisely adjusted to the clinical reality. This draft was then commented upon and criticised during four consecutive meetings of the ethics committee. During these meetings, the secretary was in constant consultation with the experts from the field of palliative care, the ethical advisor of the Flemish Palliative Care Federation, and a professor in medical law. His input meant that the content of the guideline was tested against the evolving political discussions of the legal bill in the Belgian parliament.

- The third draft of the guideline was presented to the personnel (physicians and nurses) of three healthcare institutions (one general hospital, one psychiatric hospital, one nursing home) and criticised. The guideline was again revised to become even more concrete.
- Lastly, after the guideline was completed, it was presented for approval to the board of directors of Caritas Flanders by the ethics committee. The guideline was approved on the 26 April 2002.

\section{CLINICAL PRACTICE GUIDELINE FOR EUTHANASIA REQUESTS FROM COMPETENT, TERMINALLY ILL PATIENTS \\ Palliative care for all}

The starting point of the clinical practice guideline is the principle that everything possible should be done to provide support to the competent, terminally ill person who requests euthanasia, and his or her relatives. The ethics committee of Caritas recommended therefore that every dying person should have the right to expert medical and nursing care, in the framework of dignified integral care. The recognition of this basic right can best be ensured by setting up a structure and a culture of palliative care.

The ethics committee supports the general opinion that good palliative care is considered to be a sine qua non of euthanasia, for the problem of the control of suffering still remains. ${ }^{4-7}$ What then has to be done? The first thing to do is to try to present the occurrence of those situations for which euthanasia has been suggested, by anticipating their onset and forestalling their development. ${ }^{8}$ The second thing is to provide terminal patients with the choice of all methods of relief and control of distressing symptoms that are now available..$^{8-10}$ Finally, it must be recognised that the care of the patient and the relief of his or her suffering are never purely medical concerns, and we must thus provide for his or her physical, mental, and spiritual wellbeing by involving all the caring professions in an effective, sensitive, and supportive approach to the patient and his or her family. ${ }^{11-13}$ For this reason, the consulting physician should, at an early stage, need to appeal to the expertise of a specialised palliative support team in order to discuss the palliative possibilities and to apply them in a way that alleviates the patient's suffering as much as possible. ${ }^{5}$

When it becomes clear that a terminal patient's pain and distress cannot adequately be combated using "normal" palliative methods, the technique of palliative sedation could be taken into consideration. ${ }^{14}{ }^{15}$ In the context of palliative care, palliative sedation refers to "the intentional administration of sedative drugs in dosages and combinations required to reduce the consciousness of a terminal patient as much as necessary to adequately relieve one or more refractory symptoms" ${ }^{\prime 14}{ }^{15}$ Palliative sedation is only considered when one is confronted with a refractory symptom which causes the patient enormous suffering and prevents a dignified death. A symptom can be considered refractory to treatment when it cannot be adequately controlled in spite of every tolerable effort to provide relief, within an acceptable time period without compromising consciousness. ${ }^{15}{ }^{16}$ The most frequent reasons for inducting sedation are delirium, dyspnoea, and pain, ${ }^{17}{ }^{18}$ but psychological symptoms can also be considered as refractory. ${ }^{17} 19$

\section{When termination of life is requested}

Attentively listening to a request for euthanasia

A request for euthanasia is in the first place a signal that the patient gives to elucidate their views towards being ill, the physical pain, the possible deterioration that can come, the hopeless nature of the situation. Each euthanasia request must therefore be open to discussion, even if medically speaking the actual dying is still far away. It is essential that the caregiver shows his or her willingness to listen to the patient requesting euthanasia, while at the same time ensuring the decision of the patient is based on an 
autonomous, free, and informed choice. To this end, the following questions should be posed: ${ }^{20}$

- What motivation lies at the ground of the request for euthanasia? Is this really a request to put actively an end to their life, or is the patient asking for caring guidance in the last days or weeks of their life?

- Does the patient have sufficient information (for example, diagnosis and prognosis) on the grounds on which they make their request?

- Is the patient mentally competent at the moment when making their request?

- Has the patient discussed their euthanasia request with other people?

- Does the patient make the request voluntarily? Is there no question of any form of coercion or pressure?

\section{The palliative filter procedure}

It would be contrary to the guidelines concerning care for a dignified end of life if a request for euthanasia were to be ignored by the physician when medical decision making takes place. On the other hand however, the patient's request is by itself a necessary but not sufficient reason for initiating euthanasia. The Caritas ethics committee emphasises-even more so than the Belgian legislation does - the importance of adequately implementing palliative possibilities. Caritas Flanders explicitly installs the so called palliative filter procedure. The aim of the palliative filter procedure is to ensure all palliative possibilities are investigated, and that all involved thoroughly consult each other on the euthanasia request as well as the remaining palliative possibilities. $^{7}$

The concrete possibilities of palliative care are thoroughly conferred by the attending physician with the healthcare institution's palliative support team: ${ }^{20}$

- What diagnosis and prognosis can one give of the illness?

- What estimates can one make in relation to the fighting of the symptoms?

- What treatment alternatives can one still offer the patient?

The patient is completely informed by the attending physician about all aspects of their health situation and about the existing possibilities for palliative care. In these cases, the patient will be provided with the palliative support team's recommendations and the patient will explicitly be given an opportunity to consult the palliative support team. In every case it must be communicated: ${ }^{20}$

- To whom the patient can go with questions.

- What sort of care the patient can expect.

- What happens if the patient can no longer make their own decisions.

If the patient so desires, the physician will discuss the euthanasia request with friends and family as the patient designates. Hereby the following questions can be addressed: ${ }^{20}$

- How do the relatives view the situation of the patient?

- What information about the illness and about the prognosis is known to the relatives?

- What knowledge do they have about the palliative possibilities?

- What position do the relatives take when they hear about the request for euthanasia?

- How can the relatives of the patient be supported?
The attending physician will thoroughly discuss the euthanasia request, and the patient's situation, with the nursing team: ${ }^{20}$

- The nurses must know that eventual involvement with euthanasia can never go further than nursing tasks.

- The nurses must know where they can go with the emotions that a euthanasia request can cause.

- The nurses must know that they have the right to follow their conscience with regards to the request for euthanasia, and eventually to make a conscientious objection.

The procedure just described guarantees that all terminal patients will be offered good palliative care. It is aimed by the Caritas ethics committee that the palliative filter procedure functions as a preventive measure with respect to euthanasia requests.

\section{If the euthanasia request persists}

Despite a careful implementation of the palliative filter procedure, the physician may be faced with a conflict of conscience when the patient's suffering (and the euthanasia request deriving from it) does not diminish. In these cases, the acceptance of the request by the physician to initiate euthanasia should be respected. Prerequisites for an actual decision to initiate euthanasia are:

- Assessment of the euthanasia request by means of legal criteria as they are described in Article 3.1 of the Euthanasia Act (see below).

- The consultation of a second physician. ${ }^{5}$

The attending physician will consult a second physician. The following guidelines will be followed:

- The second physician must be independent with regards to the attending physician and the patient.

- The second physician serves as an expert: they must have enough expertise to be able to evaluate whether the request of the patient was voluntary, well considered, and repeated; they must have more than an adequate knowledge of palliative care.

The second physician must follow four steps in his or her evaluation:

- A conversation must be engaged in with the attending physician about the situation of the patient and the request for euthanasia.

- The medical file of the patient must be studied.

- The patient and their request for euthanasia must be examined (that is, the presence of unbearable suffering; study of palliative alternatives; the request is voluntary, well considered, and repeated).

- A report must be written wherein the findings in relation to the above mentioned tasks are elucidated.

\section{Taking a decision}

The attending physician will only initiate euthanasia if he or she has come to the decision with the patient that, for the situation the patient finds themselves in, there is no other reasonable solution.

Despite the fact that the end responsibility for the decision about euthanasia is carried by the attending physician, it is necessary that the decision springs forth from close consultations with the other members of the healthcare team, the patient, and their relatives (see above).

In accordance with the needs of the law, the attending physician writes a report for the Federal Control and 
Evaluation Committee, and informs the concerned authorities of the euthanasia case.

\section{Some points of concern relating to shared decision making}

Many parties are always involved in decision making regarding the end of life. Besides the patient and their relatives, the physician, the nurses, and the healthcare institution play a role.

\section{The patient and relatives}

It is essential for the success of the palliative filter procedure that the patient and his or her relatives are motivated from the outset to participate in a process of joint exploration with regards to possible courses of action. The underlying idea is that it cannot be objectively determined in advance what is best in a given situation, but that this can only be discovered by relating various points of view on the matter. ${ }^{21}$ This communication process can identify possible pseudo questions and pseudo solutions (based on incomplete or inaccurate information).

Decision making regarding the end of life cannot be conceived of as a "one off" act by an individual (for example, a patient who demands euthanasia with no further discussion), but as a process of interpersonal agreement (patient, relatives, physician, nurses, and palliative support team who enter into a dialogue). The ideas of the various parties in this decision making process are not considered to be fixed facts leading to immediate action, but as the object of a communal exploration and discussion. ${ }^{21}$ This process oriented approach does not mean that the patient's will is unimportant. The patient's wishes are crucial, but in many cases (especially in the first requests for euthanasia) they cannot be formulated simply. In many cases, the precise content of the patient's will must be explored and further refined, even for the patient themselves. The will of a patient cannot replace dialogue. To the contrary, it is only through common exploration and deliberation that the genuine will of the patient can gradually become clear. For this reason, interpersonal dialogue can be seen as an essential form of respect for the patient's will.

\section{Nursing team}

Because of the intertwining of both medical and nursing aspects in care for a dignified end of life, physicians and nurses should develop good cooperative relationships with respect for one another's contributions.

The patient's request for euthanasia will not always, or not in the first instance, be directed at the physician: usually it is directed at the nurse. ${ }^{22}$ In this initial phase, the nurse's specific task includes being receptive to the signals that might contain a wish to die and communicating this information to the physician (unless the patient explicitly forbids this). It is also important for the nurse to carefully observe and assist the patient, for instance by paying close attention to how the patient emotionally processes information. The nurse must also be attuned to the relations and the discussions with the patient's friends and family.

If the physician is the first one to be confronted with the euthanasia request, they should follow the guideline that this request should be discussed with the members of the nursing team who are directly involved in caring for the patient (unless the patient explicitly forbids this).

When a nurse is involved in directly caring for a patient who makes a euthanasia request, they should participate in the decision making process that accompanies the implementation of this clinical practice guideline, as the nurse's daily involvement and their specific expertise mean that they will be able to make a significant contribution to finding a solution to the patient's request.

Ultimate responsibility for all end of life decisions rests with the physician, because of their medical expertise and legal competence.

\section{Healthcare institution}

Given the complexity of the decision making and the diversity of professional backgrounds among the parties involved, the healthcare institution's local ethics committee should formulate recommendations concerning care for a dignified end of life. In so doing, explicit attention should be given to dealing with euthanasia requests.

It is recommended that guidelines on care for a dignified end of life are made known inside and outside the healthcare institution walls, so that prospective patients and (prospective) staff members know what to expect. ${ }^{23}$

\section{DISCUSSION AND CONCLUSION}

The debate on euthanasia in Belgium leads Caritas Flanders to believe that caregivers will increasingly be confronted with euthanasia requests and will therefore be more involved in care for these patients. With this clinical practice guideline, Caritas Flanders tries to contribute to greater transparency and clarity of policy regarding clinical practice. This initiative of Caritas Flanders could be considered within the increasing need for written policies and practice guidelines on medical decisions concerning the end of life, which is in line with the general tendency towards developing guidelines in modern medicine. Some of the reasons mentioned for the usefulness of written guidelines are that they may be helpful as a practical guide in work, define the responsibilities of caregivers, and serve as a cornerstone for quality. ${ }^{3}$ It is only recently that the need for practice guidelines on handling requests from patients for euthanasia has gradually received international recognition. ${ }^{3} 2425$

Although this guideline is in the first place practice oriented, the clinical application of this guideline makes clear that the fields of medicine, ethics, and law are intertwined. Caregivers will use this guideline to improve the quality of the care for patients who request euthanasia. However, the decisions caregivers take at the end of life are not purely "medical" but also "ethical" decisions. Questions of human dignity, meaningfulness, and quality of life transcend the clinical discourse and require an ethical judgment. Finally, concrete clinical practice, and the accompanying ethical decision making process, will be influenced by the legal perspective, which focuses on what one has to do in order not to be prosecuted. Most of the points that have been taken up in the clinical practice guideline are also present in the euthanasia law. The importance of the guideline, in terms of clinical practice, is in the way that an effort has been made to integrate the purely legal testing of the euthanasia request in a wider ethical framework concerned with death with dignity. In this way, the decision making process gets less of a bureaucratic character and is instead seen in terms of a clinical-ethical dialogue. In such a process of clinical-ethical decision making, the three perspectives-clinical, ethical, and legal-cannot be separated from one other. To the contrary, clinical competence, ethical awareness, and legal regulation permit caregivers to be a "skilled companion" for patients who request euthanasia, a companion who is willing to encounter the patient as a person, to ascertain his or her needs and, together with the patient, to seek the most dignified answer in an interdisciplinary context. Further empirical research in terms of the actual functioning of the clinical practice guideline developed by Caritas Flanders is needed. This will allow evaluation of how successful the guideline has been in building bridges 
between ethics, law, and clinical practice in terms of caring for patients who request euthanasia.

The style of ethical argumentation that is used in this guideline is referred to as "clinical ethics". In clinical ethics, the focus is on the ethical aspects of the factual clinical situation with attention to the patient's expectations, experiences, and so on, as well as the professional and personal experiences of the caregivers. To make this guideline relevant for clinical practice, where possible, experiences of experts are integrated. More importantly, the palliative filter procedure that occupies a central place in this guideline is based on the expertise of the Flemish Palliative Care Federation (a pluralistic organisation that unites all Flemish palliative care services). ${ }^{7}$ This organisation has been proactively involved in the debate on the contents of the euthanasia law in Belgium, highlighting that if euthanasia can ever be justified, it is necessary to provide good palliative care for all and to include in the euthanasia law a palliative filter-that is, a compulsory prior consultation with a specialised palliative care team. Besides this contribution of the Flemish Palliative Care Federation, in the development of this guideline, we were confronted with a lack of empirical studies that describe the experiences of caregivers concerning their involvement in the care for patients who request euthanasia. More specifically, apart from the Netherlands, ${ }^{5} 2023$ studies regarding caregivers' experiences with clinical practice guidelines in terminal care were nonexistent. Caregivers who speak on the basis of their own experience can focus attention on important aspects of the contents and the functions of clinical practice guidelines in end of life care. Further research into the use of clinical practice guidelines and their contribution to the care for patients who request euthanasia is therefore needed. More specifically, research (effect study) into the implementation and application of the clinical practice guideline of Caritas Flanders has to be conducted. Relevant questions to be answered are: Are those who are to make use of this guideline aware of both the existence and the content of the guideline? Do they accept the guideline? Are they sufficiently satisfied with the guideline to continue using it? Research in the Netherlands found that compliance with the guidelines on euthanasia or assisted suicide, if present, is quite high. ${ }^{23}$ The reported high rate of compliance with the euthanasia guidelines is possibly explained by the fact that euthanasia involves a practice with considerable implications, and the guidelines can actually offer support to the physician. In order to improve its usefulness, the centrally developed guideline of Caritas Flanders should preferably form the basis of policy development at local level-that is, at institutional level. At this local level, the guideline can, if necessary, be amended to suit to each individual situation. Individual opinions and interpretations can be incorporated, which could serve to broaden the basis and increase the applicability of the guidelines. ${ }^{3}$

The starting point of this clinical practice guideline is the principle that everything possible should be done to provide support and assistance to the competent, terminally ill person who asks for euthanasia, and his or her relatives. The aim is that such an active and integral palliative care approach can in many cases displace the request and allow the patient to die in a dignified manner without euthanasia. This means that healthcare institutions should think of palliative care as an active and integral approach employed in the case of every terminally ill patient, rather than seeing it as one alternative alongside euthanasia. To interpret this argument in the right way, we have to refer to the developments in the field of palliative care in Belgium. The plea for the palliative filter procedure is only credible if a sufficiently strongly developed and accessible palliative care structure exists. In Belgium, the development of palliative care preceded the euthanasia debate. $^{26}$ As a result, Belgian palliative care (for example, the Flemish Palliative Care Federation) played a very active role in the Belgian euthanasia debate. The Belgian euthanasia debate itself functioned as a lever that facilitated the further development of palliative care, as is illustrated by the new law on palliative care that was approved at the same time as the euthanasia law. Because of a very fruitful cooperation between palliative care and the Belgian authorities, a unique, comprehensive, legal, and organisational palliative care framework (palliative care at home, support teams in hospitals and nursing homes, palliative care units) was set up nationwide. This specific situation of palliative care in Belgium makes the main argument of this clinical practice guideline (prioritisation of palliative care over euthanasia) a more realistic and plausible one. Because of the close interactions between the development of palliative care in Belgium and the Belgian euthanasia debate, one can conclude that theoretical arguments for or against (legalisation of) euthanasia always have to be understood against the background of the development of palliative care in any particular country. In terms of Belgium and the Netherlands-the only two countries in the world with a euthanasia law-one could investigate to what degree national differences concerning the place of palliative care have had an influence on the content of the euthanasia debate.

\section{Authors' affiliations \\ C Gastmans, P Schotsmans, Centre for Biomedical Ethics and Law, Leuven, Belgium \\ F Van Neste, University of Antwerp, Belgium}

\section{REFERENCES}

1 Deliens L, Mortier F, Bilsen J, et al. End-of-life decisions in medical practice in Flanders, Belgium: a nationwide survey. Lancet 2000;356:1806-11.

2 Huttin C. The use of guidelines to improve medical practice: main issues in the United States. Int J Qual Health Care 1997;9:207-14.

3 Haverkate I. Policies and guidelines on medical decisions concerning the end of life in Dutch health care. Amsterdam: Thela Thesis, 1999.

4 Oxenham D, Boyd K. Voluntary euthanasia in terminal illness. In: Clark D, Hockley J, Ahmedzai S, eds. New themes in palliative care. Buckingham, PA: Open University Press, 1997:275-87.

5 Onwuteaka-Philipsen BD, van der Wal G. A protocol for consultation of another physician in cases of euthanasia and assisted suicide. J Med Ethics $2001 ; 27: 331-7$

6 Quill TE, Lo B, Brock DW. Palliative options of last resort: a comparison of voluntary stopping eating and drinking, terminal sedation, physicianassisted suicide, and voluntary active euthanasia. JAMA 1997;278:2099-104.

7 Broeckaert B, Janssens R. Palliative care and euthanasia: Belgian and Dutch perspectives. Eth Perspectives 2003;9:147-64.

8 Doyle D, Hanks G, MacDonald N, eds. Oxford textbook of palliative medicine, 2nd edn. Oxford: Oxford University Press, 1998.

9 Block SO, Billings JA. Patient requests to hasten death: evaluation and management in terminal care. Arch Intern Med 1994:154:2039-47.

10 Back AL, Wallace Jl, Starks HE, et al. Physician-assisted suicide and euthanasia in Washington State: patient requests and physician responses. JAMA 1996;275:919-25.

11 Chochinov HM. Dignity-conserving care: a new model for palliative care. JAMA 2002;287:2253-60.

12 Chochinov HM, Tataryn D, Clinck JJ, et al. Will to live in the terminally ill. Lancet 1999;354:816-19.

13 Breithart W, Rosenfeld B, Pessin H, et al. Depression, hopelessness, and desire for hastened death in terminally ill patients with cancer. JAMA 2000;284:2907-11.

14 Porta J. Palliative sedation: clinical aspects. In: Gastmans C, ed. Between technology and humanity: the impact of technology on health care ethics. Leuven: Leuven University Press, 2002:219-37.

15 Broeckaert B, Nuñez Olarte JM. Sedation in palliative care: facts and concepts. In: ten Have H, Clarke D, eds. The ethics of palliative care: European perspectives. Buckingham: Open University Press, 2002:166-80.

16 Cherny NI, Portenoy RK. Sedation in the management of refractory symptoms: guidelines for evaluation and treatment. J Palliat Care 1994;10:31-8.

17 Fainsinger R, Waller A, Bercovici M, et al. A multicentre international study of sedation for uncontrolled symptoms in terminally ill patients. Palliat Med 2000; 14:257-65.

18 Porta Sales J. Terminal sedation: a review of the clinical literature. Eur J Palliat Care $2001 ; 8: 97-100$. 
19 Peruselli C, Digiulio P, Toscani F, et al. Home palliative care for terminal cancer patients: a survey on the final week of life. Palliat Med 1999; 13:233-41.

20 Koninklijke Nederlandse Maatschappij tot bevordering der Geneeskunst \& Nieuwe Unie '91. Guidelines on euthanasia for physicians and nurses: cooperation and professional tasks of physicians and nurses in euthanasia procedures, Utrecht, 1997. 3rd edn [in Dutch].

21 Widdershoven G. Ethics in the clinic: current approaches in health care ethics. Amsterdam: Boom, 2000 [in Dutch].

22 De Beer T, Gastmans C, Dierckx de Casterlé B. Involvement of nurses in euthanasia: a review of the literature. J Med Ethics 2004 (in press).
23 Haverkate I, van der Wal G, van der Maas PJ, et al. Guidelines on euthanasia and pain alleviation: compliance and opinions of physicians. Health Policy 1998:44:45-55

24 Drickamer MA, Lee MA Ganzini L. Practical issues in physician-assisted suicide. Ann Intern Med 1997;126:146-51.

25 Caplan AL, Snyder L, Faber-Langendoen K. The role of guidelines in the practice of physician-assisted suicide. Ann Intern Med 2000;132:476-81.

26 Broeckaert B, Schotsmans P. Palliative care in Belgium. In: ten Have H, Janssens R, eds. Palliative care in Europe: concepts and policies. Amsterdam: IOS Press, 2001:31-42. 